\title{
ALTERAÇÃO NA ESTRUTURA DIAMÉTRICA DE UMA FLORESTA OMBRÓFILA MISTA NO PERÍODO ENTRE 1979 E 2000 ${ }^{1}$
}

\author{
Luciano Budant Schaaf ${ }^{2}$, Afonso Figueiredo Filho ${ }^{3}$, Franklin Galvão ${ }^{4}$ Carlos Roberto Sanquetta ${ }^{4}$
}

\begin{abstract}
RESUMO - Com o objetivo de estudar as alterações na estrutura diamétrica ocorridas numa Floresta Ombrófila Mista localizada na Estação Experimental da Universidade Federal do Paraná (UFPR) (São João do Triunfo, PR), nove parcelas, totalizando nove hectares avaliados inicialmente em 1979, foram recuperadas e remedidas em 2000. Em 1979, todos os indivíduos arbóreos com DAP igual ou superior a $20 \mathrm{~cm}$ foram identificados e numerados e tiveram seus diâmetros medidos. Em 2000, usando os mesmos critérios de inclusão, os indivíduos que não haviam sido computados em 1979 foram considerados como ingressos e os não encontrados, como mortos. Em 1979, nos nove hectares estudados foram encontrados 2.133 indivíduos e 51 espécies; em 2000, 2.202 indivíduos e 55 espécies. A floresta apresentou uma mortalidade de 513 indivíduos $(24,05 \%)$ e um ingresso de 591 outros $(27,71 \%)$, o que representa um aumento líquido de $3,66 \%$ no número de indivíduos, no período analisado. A distribuição diamétrica do conjunto de espécies apresentou a forma decrescente, do tipo J-invertido, nas duas avaliações, entretanto a frequiência de indivíduos nas classes diamétricas superiores (acima de $50 \mathrm{~cm}$ ) aumentou significativamente em 2000. Matayba elaeagnoides e Ocotea porosa diferiram das demais espécies, sendo as únicas a não apresentar distribuição diamétrica na forma de J-invertido. Em 1979, Araucaria angustifolia tinha $11,66 \%$ de seus indivíduos localizados nas classes diamétricas acima dos $50 \mathrm{~cm}$, e as folhosas apenas 6,37\%. Em 2000, 25,42\% dos indivíduos de A. angustifolia estavam em classes acima dos $50 \mathrm{~cm}$, enquanto $8,99 \%$ das folhosas ocupavam a mesma posição. Entre as parcelas, houve variações, algumas aumentaram o número de indivíduos $(1,6,7,21$ e 22) e outras diminuíram $(10,17,18,30)$. O estudo indicou também que a permanência da espécie na futura estrutura da floresta não é garantida pela grande quantidade de indivíduos nas classes de diâmetros menores, mas sim pela capacidade de competição que a espécie apresenta.
\end{abstract}

Palavras-chave: Distribuição diamétrica, dinâmica florestal e floresta de Araucária.

\section{DIAMETRIC STRUCTURE CHANGES IN A OMBROPHYLLOUS MIXED FOREST BETWEEN 1979 AND 2000}

\begin{abstract}
Aiming to study the alterations in the diametric structure of an Ombrophyllous Mixed Forest located in São João do Triunfo (Paraná State - Brazil), nine plots of 1 ha, first evaluated in 1979, were recovered and measured in 2000. In 1979, all trees with $\mathrm{dbh} \geq 20 \mathrm{~cm}$ were identified, tagged and had the dbh measured. In 2000, based on the same criteria described before, the trees which had not been counted in 1979 were considered as ingrowth and the missing ones were considered mortality. In 1979, the sample (9 ha) had 2.133 trees of 51 species. In 2000, the number of trees increased to 2.202 and the species to 55. During this period, the mortality amounted to 513 trees $(24.05 \%)$ and the ingrowth to 591 trees $(27.71 \%)$
\end{abstract}

\footnotetext{
${ }^{1}$ Recebido em 02.04.2005 e aceito para publicação em 10.11.2005.

${ }^{2}$ Programa de Pós-Graduação em Engenharia Florestal da UFPR. E-mail: <schaaf@ amazon.com.br>.

${ }^{3}$ Departamento de Engenharia Florestal da UNICENTRO e Programa de Pós-Graduação em Engenharia Florestal da UFPR. E-mail: <afig@floresta.ufpr.br>.

${ }^{4}$ Departamento de Ciências Florestais da UFPR. E-mail: <fgalvao@floresta.ufpr.br > e <sanqueta@ floresta.ufpr.br>.
} 
in the studied area, giving an increase of $3.66 \%$ in trees' density. In both evaluations, the diametric distribution of the forest (all species included) presented a progressive decrease, like a J-shaped curve, although the amount of trees in the diametric classes above $50 \mathrm{~cm}$ increased significantly in 2000. Only Matayba elaeagnoides and Ocotea porosa did not present a "J-shaped" diameter distribution. In 1979, Araucaria angustifolia had $11.66 \%$ of trees in diametric classes above $50 \mathrm{~cm}$, the broadleaf (non-conifers) $6.37 \%$. In 2000, 25.42\% of the A. angustifolia trees were in classes above $50 \mathrm{~cm}$, while $8.99 \%$ of the broadleaf trees were in the same classes. Despite the increase in the forest density, some plots presented a decrease in the number of trees during the analyzed period. This study showed that is not the high frequency in smaller diameters classes that guarantees the presence of a species in the future forest structure, but its capacity to compete.

Keywords: Diameter distribution, forest dynamics and araucaria forest.

\section{INTRODUÇÃO}

De uma superfície que compreendia cerca de $37 \%$ para Maack (1968), 40\% para Carvalho (2003) e 41,5\% para Castella e Britez (2004), da área do Estado do Paraná $\left(200.000 \mathrm{~km}^{2}\right)$, atualmente a floresta com araucária, também conhecida como Floresta Ombrófila Mista, cobre, de acordo com levantamento realizado pela Fundação de Pesquisas Florestais do Paraná - FUPEF (CASTELLA e BRITEZ, 2004), apenas $0,8 \%$ de sua superfície original (cerca de $1.600 \mathrm{~km}^{2}$ ), em estágio avançado de conservação, com elevada biodiversidade.

Recuperar e conservar os remanescentes da Floresta Ombrófila Mista constituem um grande desafio, e isso não se consegue apenas pelo emprego da força da lei, pois é necessário conhecer os atributos da floresta. Segundo Maser (1994), tais atributos se referem à florística, à estrutura e à função. A florística trata das espécies vegetais, a estrutura do arranjo espacial e temporal desses elementos, e a função considera os processos ecológicos e as taxas em que eles ocorrem. Como os valores de parâmetros relacionados aos atributos de determinada tipologia florestal não são universais, é fundamental que cada unidade seja estudada, de modo a fornecer subsídios para a compreensão de seus processos funcionais, sua estrutura e sua composição florística.

Segundo Loetsch et al. (1973), a distribuição diamétrica de uma floresta é obtida através do agrupamento dos indivíduos em intervalos de diâmetro à altura do peito (DAP). Quanto à definição da amplitude dessas classes não há regra definida, sendo que em florestas normalmente se utilizam classes com amplitude de 5 cm (MACHADO et al., 1998; PULZ, 1998; PIZATTO, 1999; DURIGAN, 1999)e 10 cm (LONGHI, 1980; GAUTO, 1997). Coraiola (1997) empregou classes de $5 \mathrm{~cm}$ para análises referentes a grupos de espécies e classes de $10 \mathrm{~cm}$ de amplitude para análise da floresta inteira. Entretanto, Barros (1980), estudando o comportamento do ajuste de vários modelos em relação à amplitude de classe diamétrica para a Floresta Amazônica, concluiu que o intervalo de classe que proporcionou o melhor ajuste foi o de $10 \mathrm{~cm}$.

Loetsch et al. (1973) classificaram as distribuições diamétricas em três tipos principais: a) a unimodal, característica de plantios jovens e eqüiâneos; b) a decrescente, que é característica de florestas, plantios bem manejados ou considerados em conjunto (um estado ou um país); e c) a multimodal, com pouca importância nos estudos florestais, sendo raramente encontrada em florestas.

Assume-se que, em florestas equilibradas, a distribuição diamétrica dá-se na forma de J-invertido (MEYER, 1943, 1952, 1953; LEAK, 1964), que pode ser descrita por um quociente "q" (DeLIOCOURT ${ }^{1}$ ). O quociente "q" expressa a razão entre o número de indivíduos em uma classe de diâmetro e o número de indivíduos em uma classe diamétrica adjacente. $\mathrm{O}$ valor é baseado no pressuposto declínio no número de indivíduos entre classes diamétricas subseqüentes e no tamanho do maior indivíduo (OLIVER e LARSON, 1996).

\footnotetext{
${ }^{1}$ De LIOCOURT, F. De l'aménagement des sapiniéres. Bull. de la Société Forestiére de Franche-Compté el Belfort Besancon, France, 1898. Forstliche Bundesversuchsanstalt, Austria, 1971. p. 69-83
}

\author{
R. Árvore, Viçosa-MG, v.30, n.2, p.283-295, 2006
}


Segundo Husch et al. (1982), uma distribuição diamétrica pode ser testada em relação à conformidade com a definição de estrutura balanceada, através da verificação da linearidade quando se faz o gráfico do número de indivíduos (em escala logarítmica) pelas classes diamétricas.

Se em florestas plantadas a distribuição diamétrica é função basicamente da idade como expresso por Suzuki ${ }^{2}$, citado por Peden et al. (1973), nas florestas naturais essa suposição se torna questionável.

Segundo Oliver e Larson (1996), como os indivíduos arbóreos crescem à medida que envelhecem, tem-se assumido que o diâmetro pode ser substituído pela idade para representar a distribuição etária de uma comunidade. Entretanto, concluíram que extrapolar a distribuição baseada no tamanho dos indivíduos para uma distribuição de idades pode ser bastante comprometedor. Além disso, em povoamentos multiespecíficos, indivíduos finos não são necessariamente mais novos que indivíduos mais grossos.

Baseando-se em vários autores, Oliver e Larson (1996) afirmaram que, muitas vezes, uma combinação de espécies ou grupos de espécies mostra uma distribuição diamétrica na forma de um J-invertido, mesmo quando, individualmente, espécies ou grupos apresentam distribuição normal.

Segundo Husch et al. (1982), a estrutura de uma floresta, isto é, a distribuição dos indivíduos em classes de diâmetro, muda de ano para ano, devido ao crescimento, à morte e ao corte.

A maneira mais adequada para entender o desenvolvimento da distribuição diamétrica da floresta é monitorá-la sistematicamente e por longos períodos. A metodologia conhecida mais indicada para tal finalidade é a instalação e medição de parcelas permanentes. Goldsmith e Harrison (1976) afirmaram que mudanças na vegetação em longos períodos são mais bem estudadas através de parcelas permanentes ou de transectos permanentes. Para Alder e Synnott (1992), uma amostragem da dinâmica, utilizando parcelas permanentes, concentra-se inicialmente na medição de taxas de mudança, incluindo o incremento diamétrico e a taxa de mortalidade e de ingresso. Todavia, a instalação e, principalmente, o acompanhamento dessas parcelas podem ser considerados fatos recentes no Brasil, principalmente se comparados com a velocidade com que os processos dinâmicos e a eliminação das florestas ocorrem.

Este estudo teve por objetivo avaliar a alteração na distribuição diamétrica, com o uso de parcelas permanentes instaladas em 1979 e remedidas no ano 2000, em um remanescente de Floresta Ombrófila Mista localizada no Município de São João do Triunfo, Estado do Paraná.

\section{MATERIAL E MÉTODOS}

\subsection{Características da área de estudo}

Este estudo foi feito na Estação Experimental da Universidade Federal do Paraná, localizada no Município de São João do Triunfo, cerca de $125 \mathrm{~km}$ de Curitiba, Estado do Paraná - Brasil, no Segundo Planalto. A altitude do local é de $780 \mathrm{~m}$ s.n.m. e possui coordenadas geográficas de $25^{\circ} 34^{\prime} 18^{\prime \prime} \mathrm{S}$ e $50^{\circ} 05^{\prime} 56^{\prime \prime} \mathrm{W}$. A área total da floresta é de 32,36 ha, dividida em 32 parcelas, com área aproximada de 1 ha $(100 \times 100 \mathrm{~m})$ cada.

De acordo com a classificação climática de Köppen, a região apresenta clima do tipo $C f b$ (LONGHI, 1980; RODRÍGUEZTELLO, 1980; PIZATTO, 1999; DURIGAN, 1999), caracterizado por ser mesotérmico, sempre úmido e com verões brandos. O clima é típico do planalto meridional brasileiro, com temperaturas médias anuais entre $14 \mathrm{e} 19^{\circ} \mathrm{C}$ e precipitação anual entre 1.250 e 2.000 $\mathrm{mm}$. Dados climáticos médios obtidos das Estações Meteorológicas do IAPAR nos Municípios da Lapa, Fernandes Pinheiro e Ponta Grossa, próximos à área de estudo (adaptado de DURIGAN, 1999), indicam uma temperatura média anual de $17,4^{\circ} \mathrm{C}$, umidade relativa média anual de $80,1 \%$, precipitação média anual de 1.615 $\mathrm{mm}$, sendo janeiro o mês mais chuvoso e agosto, o mais seco.

Segundo Longhi (1980), baseado num levantamento realizado na área, o solo predominante é do tipo Argissolo Vermelho-Amarelo distrófico, sendo encontrado também, em pequena proporção, Cambissolo distrófico álico.

${ }^{2}$ SUZUKI, T. Forest transition as a stochastic process. In: Contributions to increment research. Forstliche Bundesversuchsanstalt, Austria, 1971.p. 69-83. 
Durigan (1999), através de prospecções realizadas também nessa Estação Experimental, identificou a ocorrência de Latossolo Vermelho-Escuro e Latossolo Vermelho-Amarelo, além de Cambissolos (Cambissolo gleico, nas cotas mais baixas) e Neossolos litólicos.

Baseando-se na classificação proposta pelo IBGE (1992), a tipologia vegetal dominante na área é a Floresta Ombrófila Mista Montana, que, apesar de não ter sofrido corte raso, é bastante alterada, enquadrando-se como uma vegetação primária muito alterada ou uma formação secundária avançada, visto que possui algumas características estruturais de formações primárias e intervenções antrópicas características de formações secundárias.

A área foi adquirida em 1969 de colonos da região, tendo sofrido corte seletivo em algumas parcelas (LONGHI, 1980). Segundo declarações do Sr. Deonízio Kieras, funcionário responsável pela Estação Experimental desde 1972, a floresta, apesar de não ter sofrido corte raso, foi alterada pelas seguintes intervenções: a) exploração seletiva de araucárias - retirada de indivíduos de grandes dimensões (antes de 1972); b) exploração de erva-mate (antes de 1972); c) corte dos indivíduos mais finos em algumas parcelas; d) incêndio que afetou as parcelas próximas à estrada (em 1982); e e) exploração e poda da erva-mate (em 1983).

\subsection{Obtenção dos dados e análises}

Este estudo fundamentou-se no levantamento realizado por Solon Jonas Longhi e Julio César Rodríguez Tello, em 1979, no qual foram coletados dados referentes a todos os indivíduos arbóreos presentes em nove parcelas de 1 ha, cujo DAP (diâmetro a 1,3 m) era igual ou superior a $20 \mathrm{~cm}$. As parcelas 1, 6, 7, 10, 17, 18, 21, 22 e 30 foram selecionadas com base na abundância de Araucaria angustifolia na fase adulta.

Foram registradas em 1979, para cada indivíduo, as seguintes informações: nome vulgar, DAP e alturas total e comercial (LONGHI, 1980). Os diâmetros foram obtidos utilizando-se uma suta, com precisão de $0,5 \mathrm{~cm}$.

Em 2000, usando o mesmo critério de inclusão, todos os indivíduos ocorrentes nas nove parcelas tiveram seus diâmetros medidos. Os diâmetros, nessa ocasião, foram obtidos com fita métrica ou trena (indivíduos maiores), com precisão de $0,5 \mathrm{~cm}$. Os indivíduos foram etiquetados com fita "rotex", e pregos.

R. Árvore, Viçosa-MG, v.30, n.2, p.283-295, 2006
Para a análise da estrutura diamétrica, considerouse a freqüência dos diâmetros em classes de amplitude de $10 \mathrm{~cm}(20-30 ; 30-40 ; \ldots ; 110-120 \mathrm{~cm})$. As análises da distribuição diamétrica foram realizadas para 1979 e 2000, considerando-se: a) a floresta ( $9 \mathrm{ha}$ ); b) as parcelas, individualmente; c) a araucária e as folhosas; e d) as espécies com maior densidade (quantidade de árvores por espécie) dessa unidade fitogeográfica.

A fim de discutir os resultados foram utilizadas ferramentas estatísticas descritivas de dados, como média, mediana, variância, coeficiente de variação, desviopadrão e assimetria em relação à curva normal. Para verificar se a distribuição diamétrica de 1979 é diferente da distribuição de 2000, foi aplicado o teste qui-quadrado $\left(X^{2}\right)$ com um nível de probabilidade $\alpha=0,01 \operatorname{com} K-1$ graus de liberdade ( $K=$ número de classes de DAP). Maiores detalhes sobre a metodologia empregada neste trabalho podem ser consultados em Schaaf (2001).

\section{RESULTADOS E DISCUSSÕES}

A distribuição diamétrica da floresta (9 ha), nos anos de 1979 e 2000, está apresentada na Figura 1.

Verifica-se, na Figura 1, que a vegetação estudada apresentou a típica distribuição J-invertido, característica de florestas - multiespecíficas e multiâneas - nos dois levantamentos efetuados, tanto em 1979 quanto em 2000, conforme constataram Pizatto (1999) e Durigan (1999) em outros levantamentos na mesma área de estudo. Contudo, nota-se que no ano 2000 houve aumento considerável na frequiência das classes diamétricas acima dos $50 \mathrm{~cm}$. Em 1979, havia 183 indivíduos com DAP igual ou superior a 50 cm e em 2000, 348 indivíduos, ou seja, um acréscimo de $90,16 \%$. O espaço está sendo ocupado por um número cada vez maior de indivíduos mais grossos, independentemente de o número total de indivíduos ter aumentado apenas 3,23\% no período, isto é, de 2.133 para 2.202. Esses fatos são indícios de que a floresta está em processo de amadurecimento.

Em 1979, a média dos diâmetros da floresta foi de $33,5 \mathrm{~cm}$, a mediana de $31 \mathrm{~cm}$ e o diâmetro máximo encontrado, de $114,5 \mathrm{~cm}$, sendo o desvio-padrão igual a $11,8 \mathrm{~cm}$, com o coeficiente de variação de $35,22 \%$ e assimetria calculada igual a 1,71, indicando desvio à direita em relação à distribuição normal, cuja assimetria é igual a zero. $\mathrm{O}$ valor da assimetria indicando desvio à direita apenas confirma o valor de a média aritmética ser maior que o da mediana. 

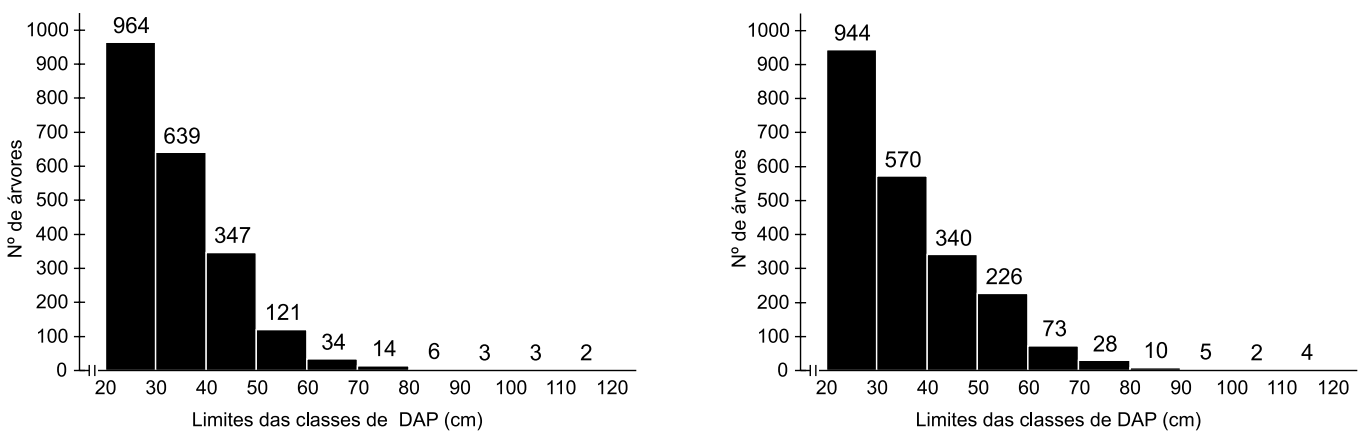

Figura 1 - Distribuição diamétrica da floresta (9 ha) nos anos de 1979 (esquerda) e 2000 (direita). Figure 1 -Diametric distribution of the forest (9 ha) in 1979 (left) and 2000 (right).

Em 2000, a média subiu para $35,9 \mathrm{~cm}$, a mediana para 32,6 cm e o valor máximo encontrado foi de 117,1 $\mathrm{cm}$. O desvio-padrão também aumentou, chegando a $13,9 \mathrm{~cm}$, e o coeficiente de variação, a $38,72 \%$, e a assimetria calculada foi de 1,42, o que indica, também, assimetria à direita.

Quando as distribuições de freqüência mostramse altamente assimétricas, como no caso da distribuição diamétrica decrescente encontrada neste estudo, devese utilizar a mediana como referência do diâmetro central da floresta, pois, ao contrário da média aritmética, não sofre a influência dos valores extremos. Assim, os dados de 1979 e 2000 apontam que o valor mediano da floresta subiu $1,6 \mathrm{~cm}$, o que confirma o fato de os indivíduos terem "engrossado", e indica também que a variabilidade dos diâmetros aumentou durante o período, com o coeficiente de variação subindo de 35,22 para $38,72 \%$.

O teste qui-quadrado aplicado para comparar as duas distribuições (1979 versus 2000) resultou bastante superior ao valor crítico $(\alpha=0,01)$, caindo na área de rejeição da hipótese nula e, portanto, as duas distribuições são diferentes, o que era esperado, tendo em vista o tempo entre as remedições ( 21 anos) e considerando que a floresta foi seletivamente explorada no passado e, ainda, está em evolução. O teste foi ainda aplicado para comparar as distribuições para folhosas e araucária (Figura 3) e para as espécies analisadas na Figura 4, com resultados iguais, ou seja, as distribuições diamétricas diferem nas duas ocasiões estudadas.

Outro dado interessante é que o grau de assimetria da floresta diminuiu no período analisado, resultado do considerável aumento do número de indivíduos nas classes diamétricas superiores e de uma pequena diminuição na freqüência das classes inferiores, o que tornou a distribuição um pouco menos abrupta (inclinada).

Quando as parcelas são analisadas individualmente, verifica-se que o padrão da distribuição diamétrica decrescente permanece, ou seja, quanto maior a classe de diâmetro, menor o número de indivíduos, conforme pode ser observado na Figura 2. Todavia, existem peculiaridades. $\mathrm{O}$ caráter decrescente da distribuição diamétrica é mais abrupto em algumas parcelas do que em outras. Por exemplo: quando são comparadas as parcelas 7 e 17, no ano 2000 verifica-se uma grande diferença na taxa de decréscimo do número de indivíduos, muito mais acentuada na primeira que na segunda. Não obstante, algumas parcelas apresentam distribuição bem semelhante, como 21 e 22 . Além disso, como pode ser observado na figura, a parcela 21 foi a que melhor conservou sua estrutura diamétrica no período.

De acordo com o Quadro 1, pode-se afirmar que as parcelas seguiram a mesma tendência da floresta para o período estudado, ou seja, todas as parcelas apresentaram aumento no número de indivíduos nas classes superiores, tanto em termos absolutos quanto em termos relativos. Com base nesses dados, podese dizer que as parcelas que mais se estruturaram (tiveram aumento no porcentual de indivíduos grossos) entre 1979 e 2000 foram as $10,17,18$ e 30 . A parcela 21 foi a que menos alterou o porcentual de indivíduos grossos presentes: 9,09\% em 1979 e 10,87\% em 2000. Diante disso, confirma-se a observação visual de que essa parcela foi a que sofreu menos alteração em sua estrutura diamétrica. 


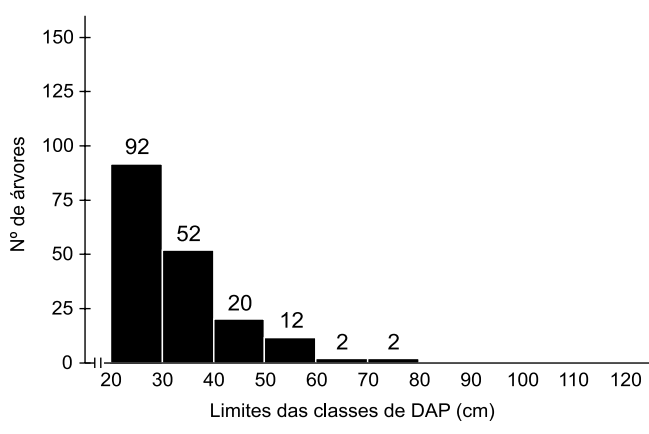

\section{Parcela 1}

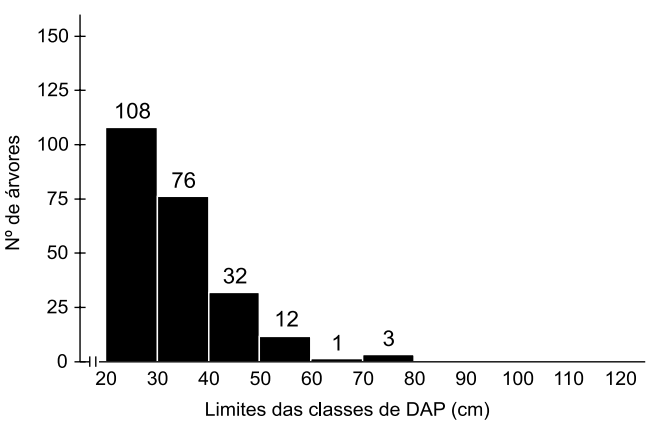

\section{Parcela 6}
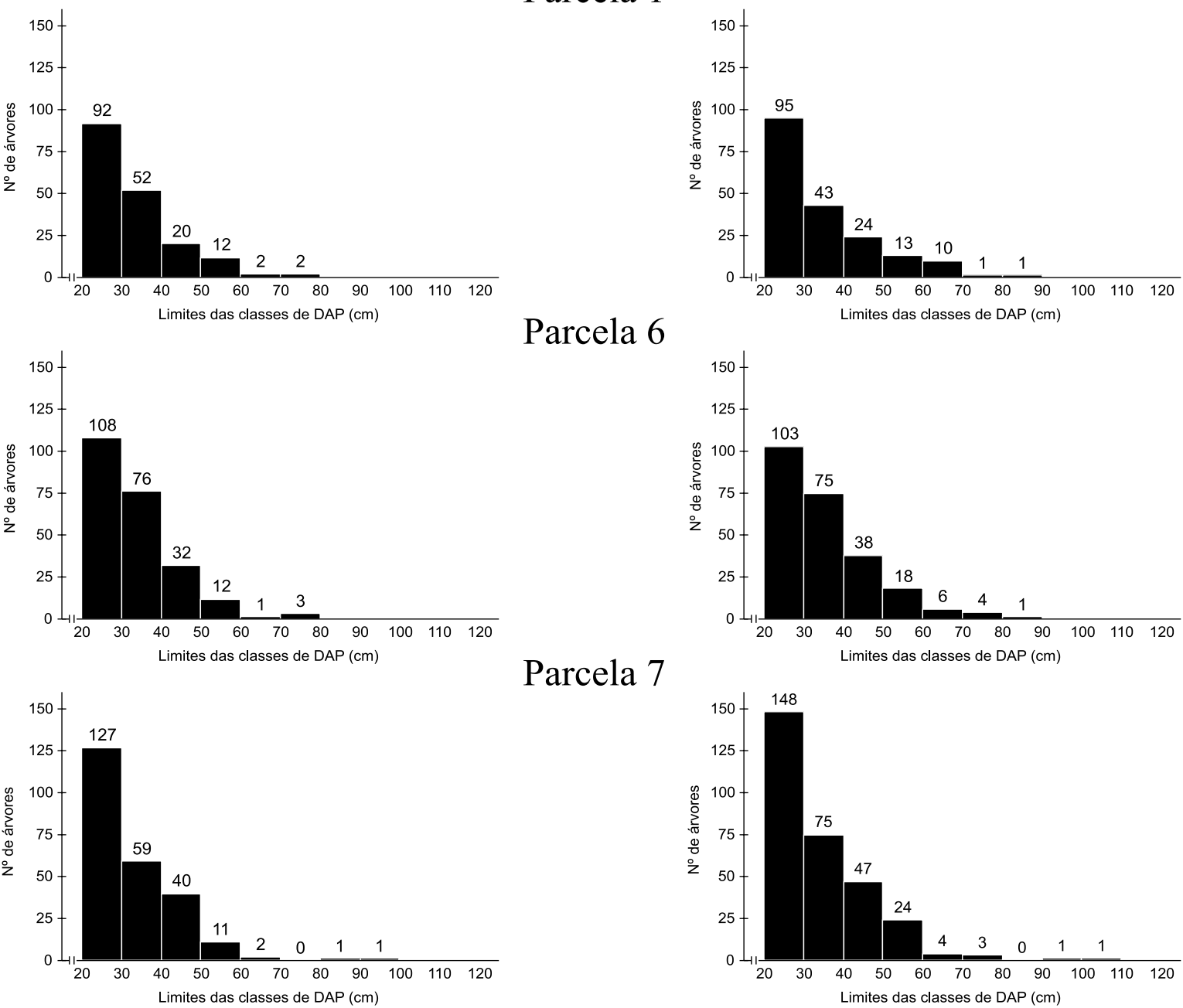

Parcela 7

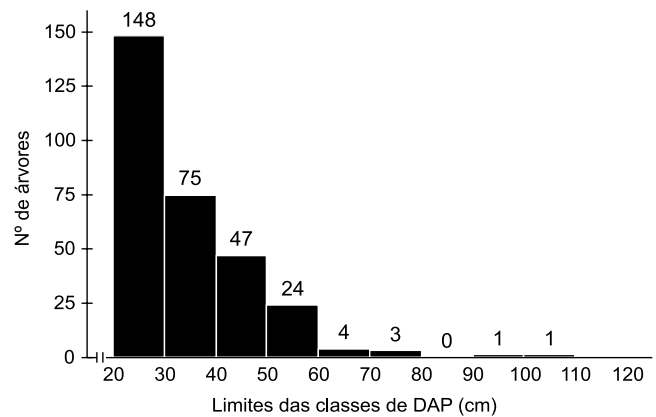

\section{Parcela 10}
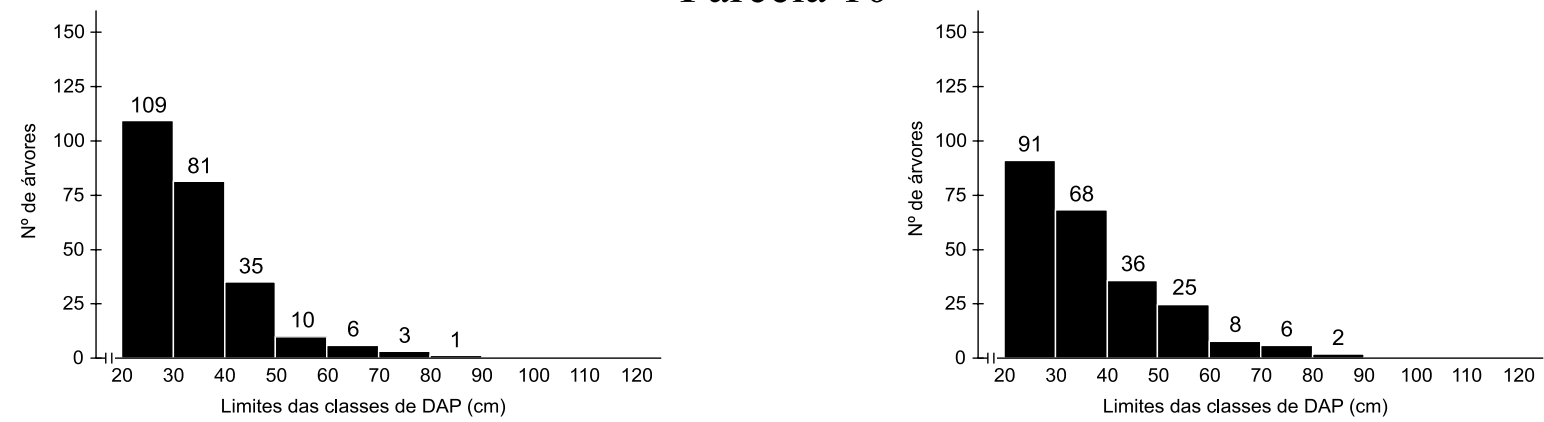

Figura 2 - Continua... Figure 2-Continued.. 


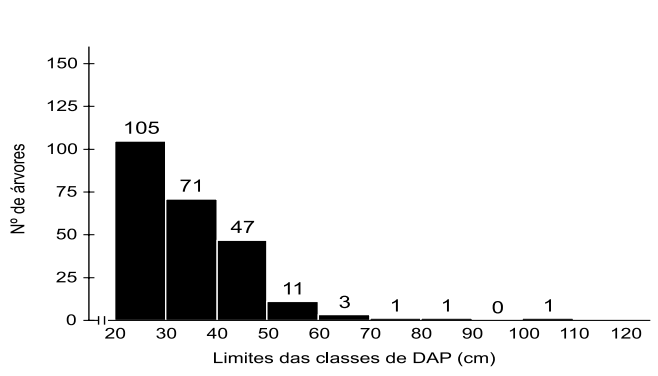

Parcela 17

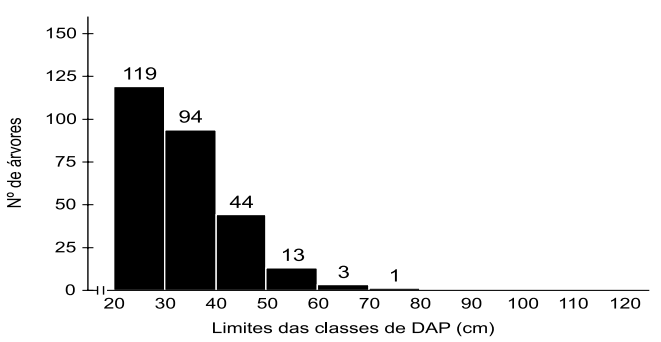

Parcela 18
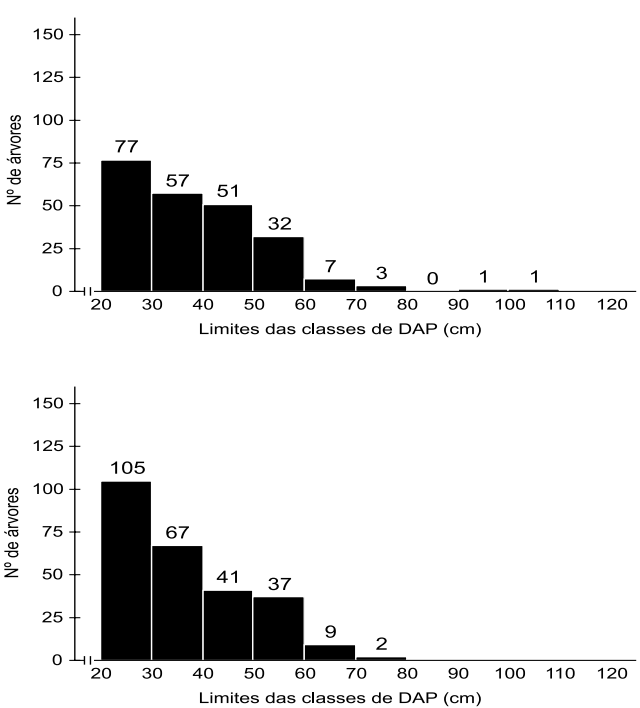

Parcela 21
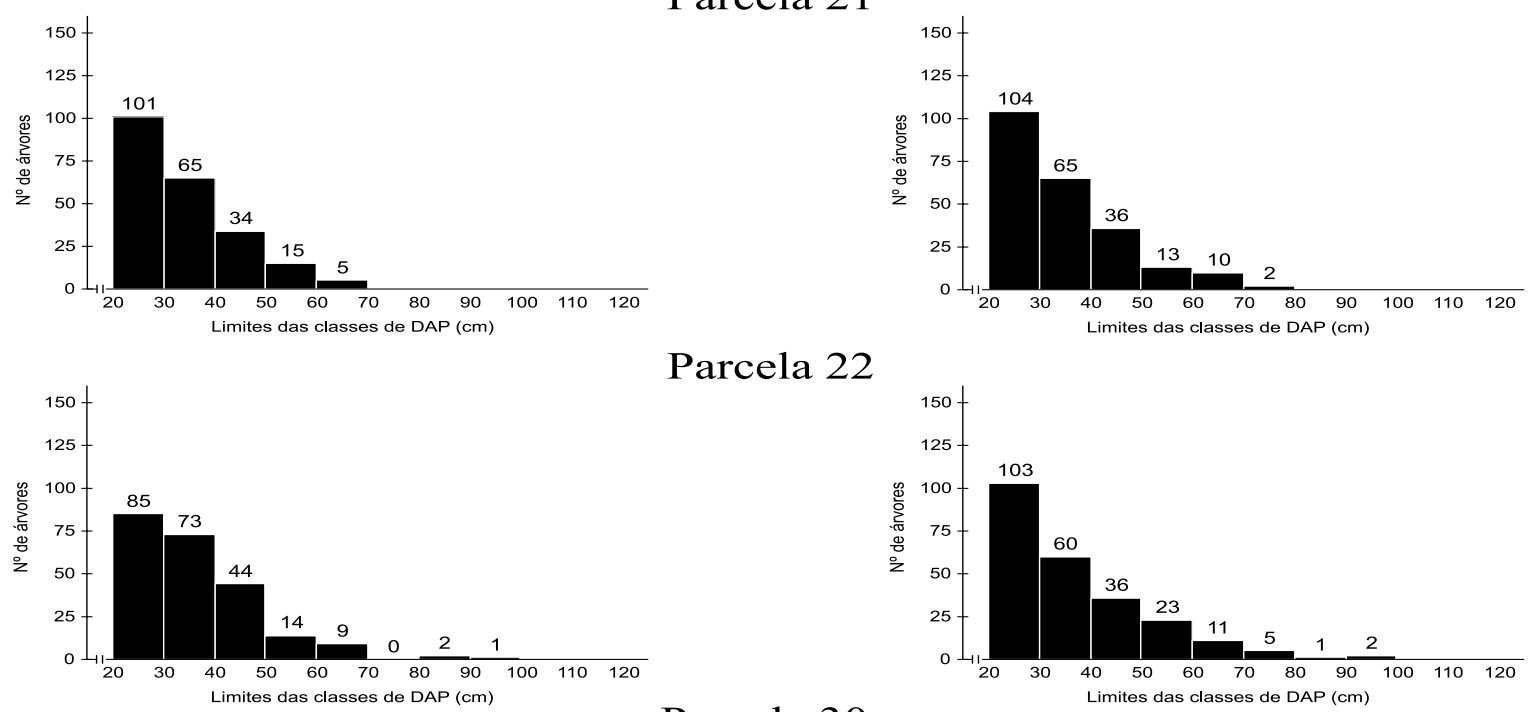

Parcela 22
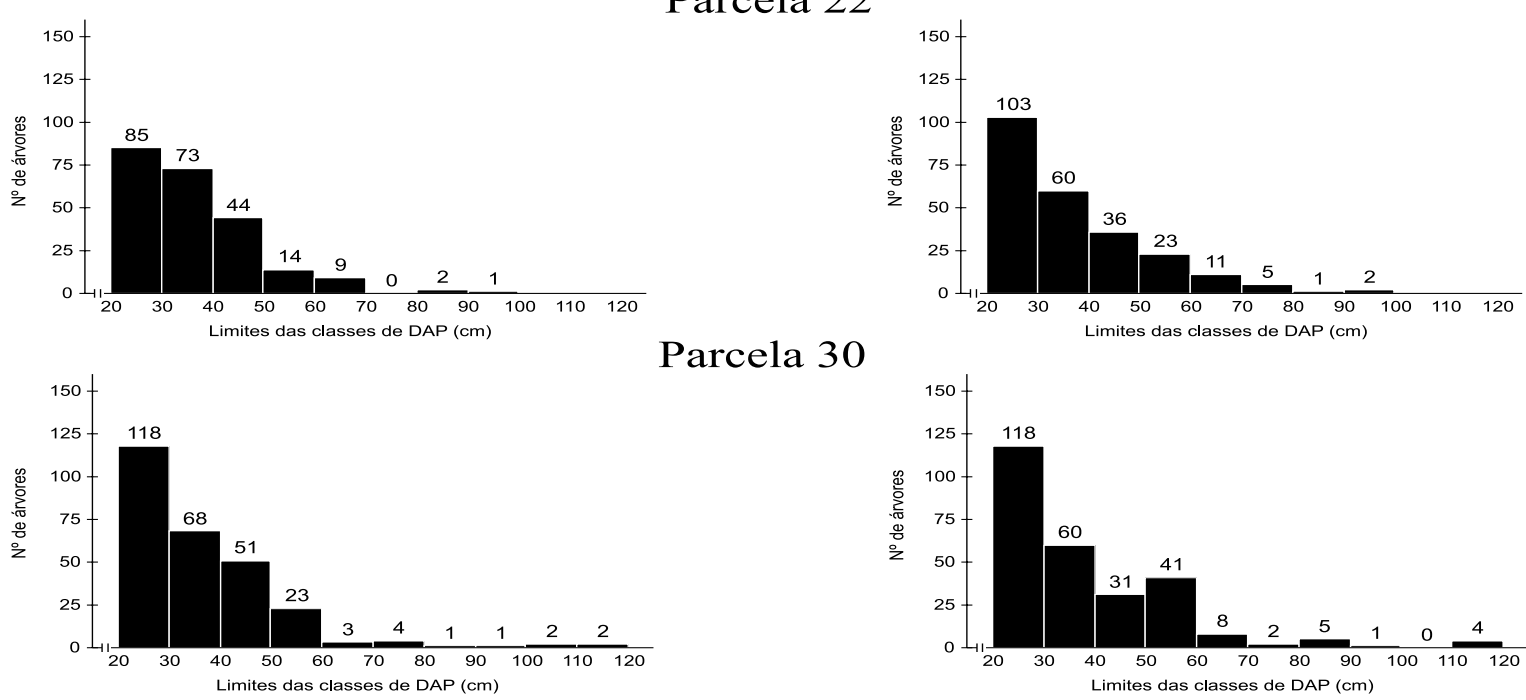

Parcela 30

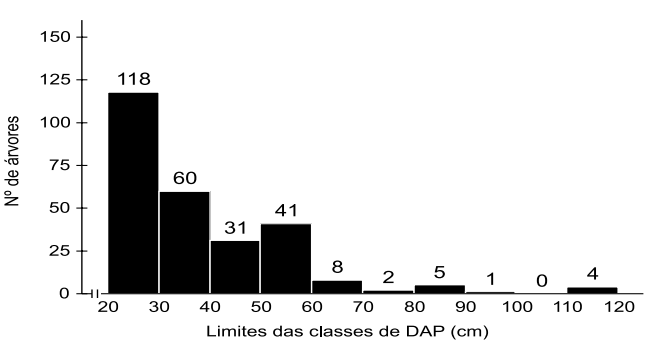

Figura 2 - Distribuição diamétrica das parcelas em 1979 (esquerda) e 2000 (direita).

Figure 2 - Diametric distribution of the plots in 1979 (left) and 2000 (right). 
Quadro 1 - Relação entre o número total de indivíduos e o número de indivíduos com $\mathrm{DAP} \geq 50 \mathrm{~cm}$ Table 1 - Relation between the total number of the trees and the number of the trees with dbh $\geq 50 \mathrm{~cm}$

\begin{tabular}{|c|c|c|c|c|c|c|c|}
\hline \multirow[t]{3}{*}{ Parcela } & \multirow{2}{*}{\multicolumn{2}{|c|}{$\begin{array}{c}\text { Número total de } \\
\text { indivíduos }\end{array}$}} & \multicolumn{4}{|c|}{ Indivíduos grossos (DAP $\geq 50 \mathrm{~cm})$} & \multirow{3}{*}{$\begin{array}{c}\text { Aumento no } \\
\text { período } \\
1979-2000\end{array}$} \\
\hline & & & \multicolumn{2}{|c|}{1979} & \multicolumn{2}{|c|}{2000} & \\
\hline & 1979 & 2000 & $\mathrm{~N}$ & $\%$ & $\mathrm{~N}$ & $\%$ & \\
\hline 1 & 180 & 187 & 16 & $8,89 \%$ & 25 & $13,37 \%$ & $4,48 \%$ \\
\hline 6 & 232 & 245 & 16 & $6,90 \%$ & 29 & $11,84 \%$ & $4,94 \%$ \\
\hline 7 & 241 & 303 & 15 & $6,22 \%$ & 33 & $10,89 \%$ & $4,67 \%$ \\
\hline 10 & 245 & 236 & 20 & $8,16 \%$ & 41 & $17,37 \%$ & $9,21 \%$ \\
\hline 17 & 240 & 229 & 17 & $7,08 \%$ & 44 & $19,21 \%$ & $12,13 \%$ \\
\hline 18 & 274 & 261 & 17 & $6,20 \%$ & 48 & $18,39 \%$ & $12,19 \%$ \\
\hline 21 & 220 & 230 & 20 & $9,09 \%$ & 25 & $10,87 \%$ & $1,78 \%$ \\
\hline 22 & 228 & 241 & 26 & $11,40 \%$ & 42 & $17,43 \%$ & $6,03 \%$ \\
\hline 30 & 273 & 270 & 36 & $13,19 \%$ & 61 & $22,59 \%$ & $9,40 \%$ \\
\hline
\end{tabular}

De maneira geral, pode-se afirmar que, em termos da estrutura diamétrica em 2000, as parcelas 10,17 , 18,22 e 30 são as mais desenvolvidas, ou seja, possuem maior número de indivíduos nas classes diamétricas superiores; já as parecelas 1, 6, 7 e 21 são as menos desenvolvidas.

A decomposição da distribuição diamétrica da floresta, em termos de sua espécie mais significativa - Araucaria angustifolia - e em termos das folhosas (todas as espécies menos Araucaria angustifolia), está apresentada na Figura 3, nos anos de 1979 e 2000.

Observa-se que a araucária apresentou distribuição decrescente, em ambos os anos (Figura 3). Esse fato confirma os resultados apresentados por Longhi (1980) para a distribuição diamétrica de Araucaria angustifolia, utilizando classes de diâmetro de $10 \mathrm{~cm}$ de amplitude; e por Pizatto (1999) e Durigan (1999), utilizando classes de $5 \mathrm{~cm}$ de amplitude, ambos obtidos nessa mesma Estação Experimental. No entanto, contraria as observações de Machado et al. (1998), que, utilizando dados de várias parcelas medidas nos Estados do Paraná e de Santa Catarina, adotando classes de diâmetro de $5 \mathrm{~cm}$, encontraram distribuições unimodais para a Araucaria angustifolia, tanto em florestas primárias quando em florestas secundárias, sendo que nas secundárias a distribuição diamétrica, apesar de unimodal, mostrou-se bastante assimétrica, tendendo para uma forma decrescente.

As folhosas, conforme mostrado na Figura 3, também apresentaram distribuições diamétricas decrescentes, nos levantamentos de 1979 e 2000 . Todavia, o grau de decréscimo apresentado por Araucaria angustifolia foi bem menor do que o das folhosas. Estas concentram nas classes inferiores, enquanto Araucaria angustifolia está mais bem distribuída ao longo das classes. Em $1979,11,66 \%$ das araucárias localizavam-se em classes acima dos $50 \mathrm{~cm}$, sendo que apenas $6,37 \%$ das folhosas ocupavam a mesma posição. Em 2000, 25,42\% das araucárias estavam em classes acima dos $50 \mathrm{~cm}$, enquanto $8,99 \%$ das folhosas ocupavam a mesma posição. Considerando que a participação relativa da araucária no número total de indivíduos subiu de 41,82 para $48,96 \%$ no mesmo período, esse resultado torna-se mais contundente. Nas condições ambientais da floresta estudada, a araucária apresenta-se claramente superior a outras espécies, em termos de competição.

A idéia geral de que grande quantidade de indivíduos nas classes inferiores (distribuição exponencial negativa) indica que uma espécie vai estar garantida na estrutura futura da floresta nem sempre é verdadeira. A araucária estava longe de apresentar tal distribuição em 1979, contudo não só manteve sua participação na floresta em 2000 , como também a aumentou. Esse fato contradiz a previsão efetuada por Longhi (1980), na qual o autor acreditava que o número de indivíduos de araucária nas classes inferiores seria insuficiente para vencer a concorrência e garantir a substituição dos indivíduos nas classes superiores, a não ser que em uma fase posterior da dinâmica da floresta essa espécie adquirisse maior vitalidade e tolerância à sombra. 


\section{Araucaria angustifolia}
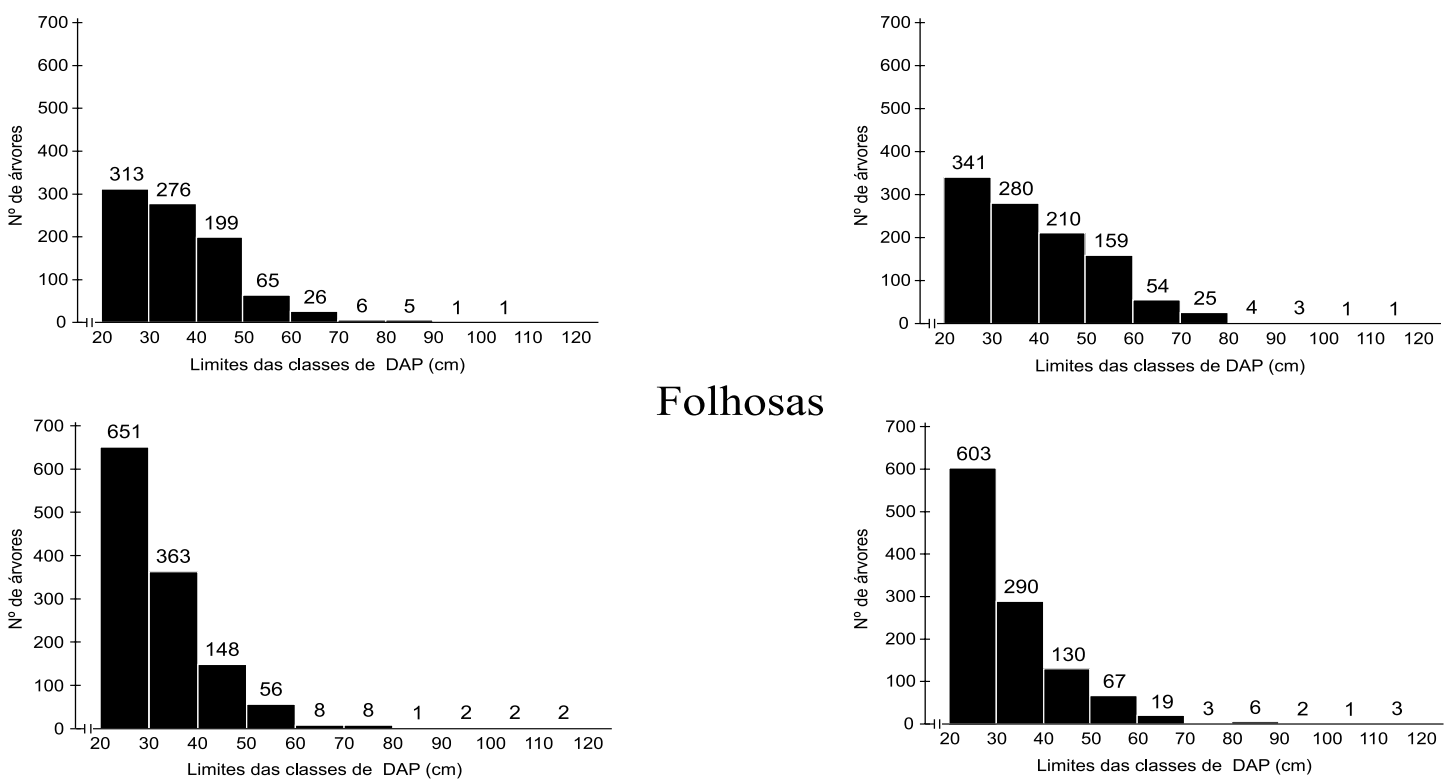

Folhosas

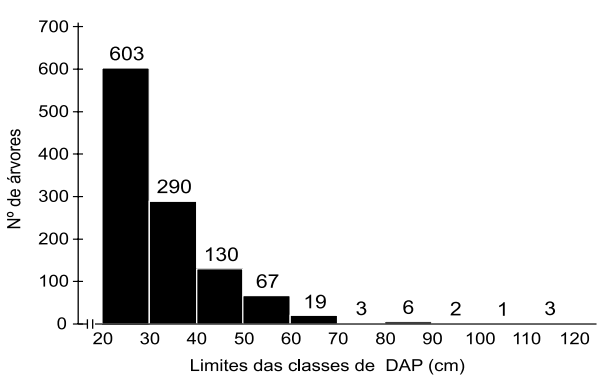

Figura 3 - Distribuição diamétrica da Araucaria angustifolia e das folhosas em 1979 (esquerda) e 2000 (direita) nas nove parcelas estudadas.

Figure 3 - Diametric distribution of the Araucaria angustifolia and broadleaf (non-conifers) in 1979 (left) and 2000 (right) at the 9 plots studied.

Se uma espécie tem poucos indivíduos nas classes inferiores, mas com pequena probabilidade de morrer devido à competição, é bem provável que tal espécie se mantenha na floresta. No entanto, uma espécie na qual grande parte dos indivíduos estão sujeitos a morrer devido ao fato de a competição necessitar apresentar uma grande frequiência nas classes diamétricas inferiores para ter alguma chance de sobreviver na comunidade. Pode-se dizer que a distribuição diamétrica reflete as características auto-ecológicas das espécies.

Com base na Figura 4, em que estão apresentadas as distribuições diamétricas das folhosas com maiores densidades dessa unidade vegetacional, observa-se a grande diversidade nos padrões de distribuição, tanto em termos de espécies quando relacionado aos períodos de medição.

Baseado na distribuição de Ilex dumosa em 1979, caso se seguisse o mesmo raciocínio empregado por Longhi (1980) para a distribuição da Araucaria angustifolia, afirmar-se-ia que a espécie teria sua participação garantida na floresta em 2000, pois apresentava uma distribuição altamente decrescente, com grande quantidade de indivíduos nas primeiras classes diamétricas. Contudo, apesar de continuar presente em 2000, não se pode afirmar que assim permanecerá nos próximos anos, visto que o número de indivíduos dessa espécie caiu de 279 em 1979 para apenas 42 no ano 2000. Essa espécie é pouco competitiva na comunidade. Não obstante, o grande número inicial de indivíduos nas classes inferiores não está conseguindo se manter na estrutura da floresta.

O comportamento oposto ao de Ilex dumosa foi apresentado por Ocotea porosa. Essa espécie, que em 1979 contava com 81 indivíduos distribuídos ao longo de todas as classes diamétricas, com relativamente poucos indivíduos nas classes inferiores, não apenas se manteve, como aumentou sua densidade absoluta para 83 indivíduos, em 2000. Além disso, Ocotea porosa acompanhou o amadurecimento da floresta, aumentando o número de indivíduos nas classes diamétricas superiores. Em 1979, 28,40\% dos indivíduos possuíam DAP maior que $50 \mathrm{~cm}$ e em 2000, 42,17\% encontravamse na mesma posição dentro da distribuição diamétrica.

R. Árvore, Viçosa-MG, v.30, n.2, p.283-295, 2006 


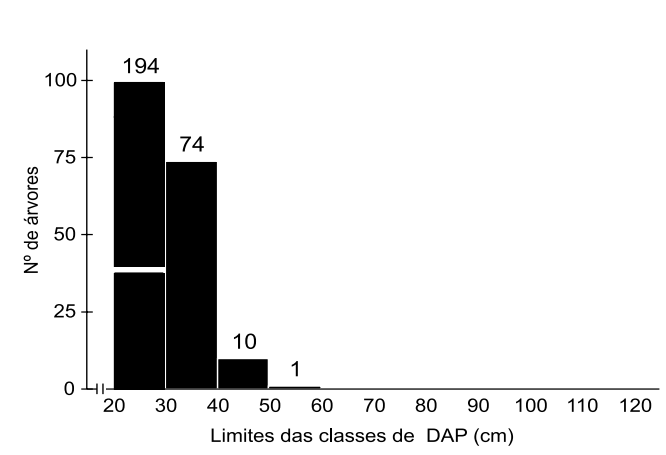

\section{Ilex dumosa}

\section{Matayba elaeagnoides}
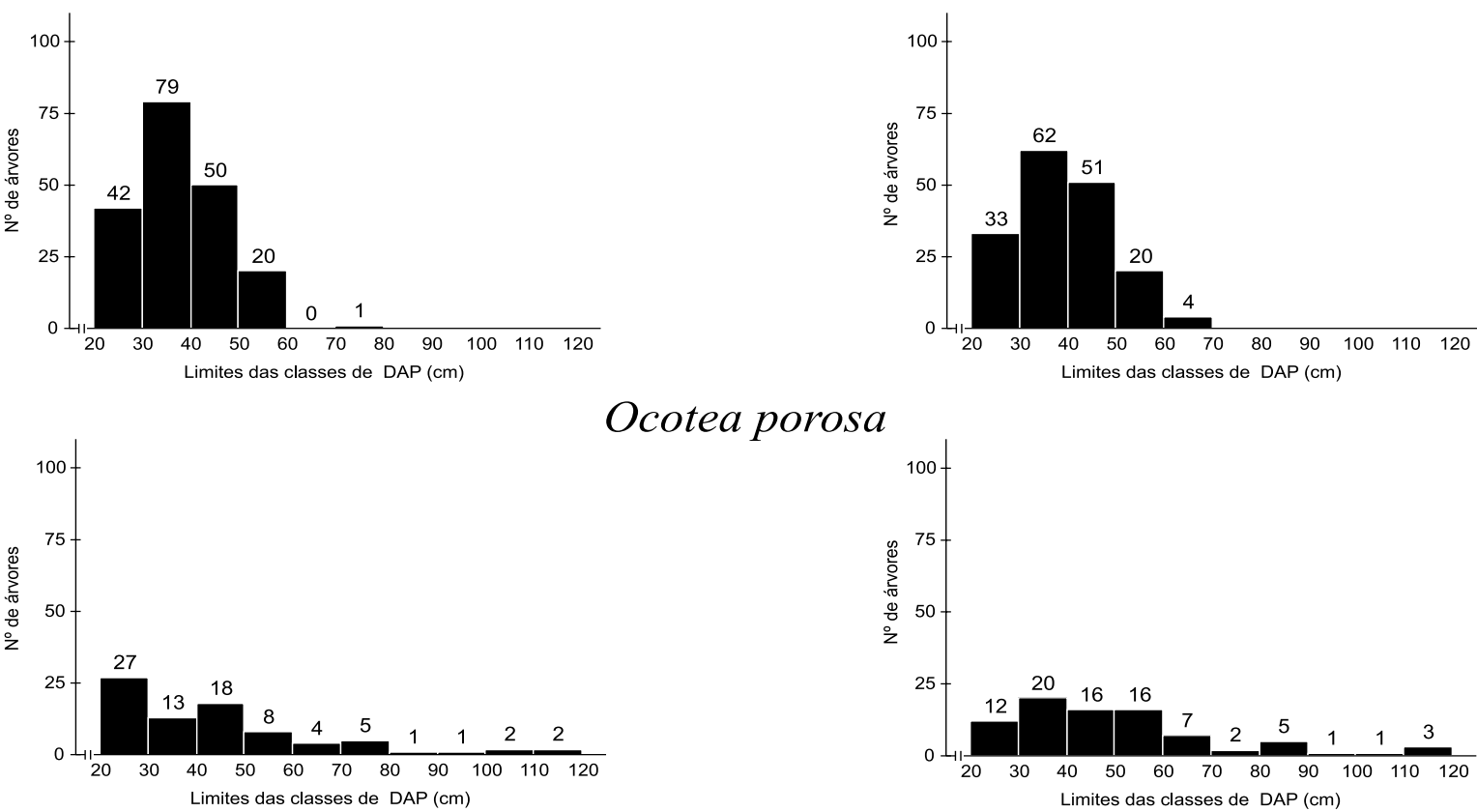

Ocotea porosa

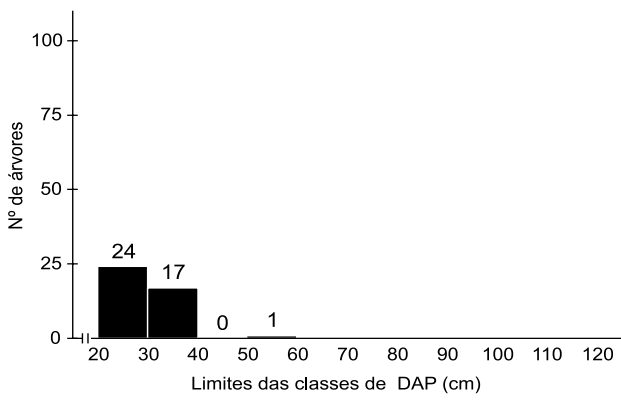



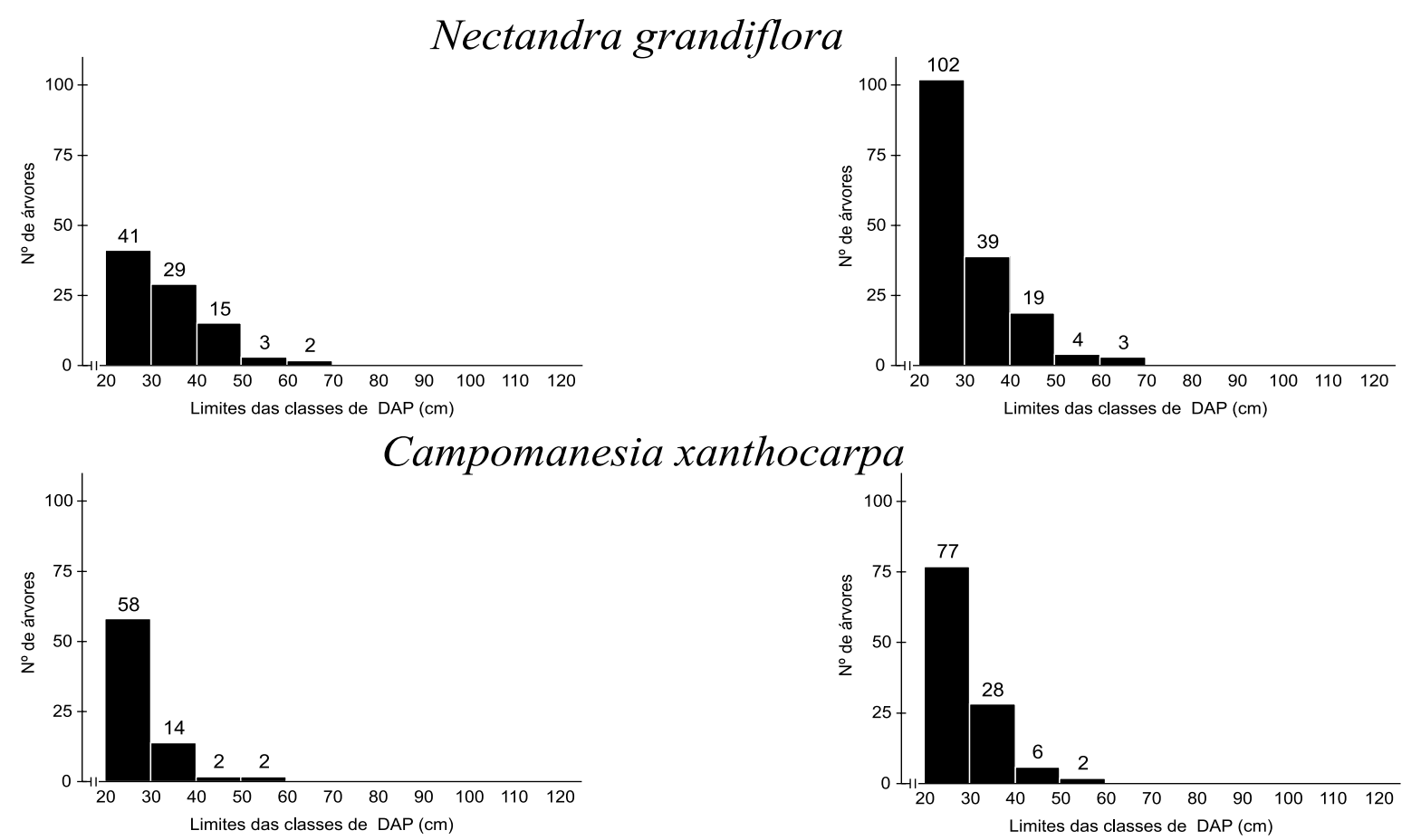

Figura 4 - Distribuição diamétrica das espécies com maiores densidades em 1979 (esquerda) e 2000 (direita) e nas nove parcelas estudadas.

Figure 4 -Diametric distribution of the species with higher number of trees in 1979 (left) and 2000 (right) at the 9 plots.

Esse fato vem mais uma vez comprovar que não é o fato de ter maior densidade que uma espécie garante sua manutenção na comunidade, mas sim sua capacidade de competir dentro do seu nicho ecológico. Portanto, para que Ocotea porosa permaneça na estrutura da comunidade, são necessários bem menos indivíduos nas classes diamétricas inferiores (ingressos) do que Ilex dumosa necessitaria.

Outra espécie que apresentou comportamento contrário ao de Ilex dumosa foi Nectandra lanceolata. Essa espécie aumentou sua densidade enormemente nas classes inferiores entre 1979 e 2000 , dando evidentes indicativos de que é mais competitiva dentro da estrutura da floresta do que Ilex dumosa.

Da mesma forma que a Nectandra lanceolata, a Campomanesia xanthocarpa confirmou sua presença na estrutura da floresta entre os anos de 1979 e 2000. A freqüência de indivíduos por classe de diâmetro aumentou em todas as classes, com exceção da classe $50-60 \mathrm{~cm}$, na qual permaneceu constante.
Outra constatação relevante, que emerge quando se analisa a distribuição diamétrica das espécies mais importantes, é a diferença interespecífica no formato das distribuições. Matayba elaeagnoides, por exemplo, apresenta uma distribuição genuinamente unimodal. Já Ocotea porosa tem tendência a apresentar uma distribuição uniforme. No entanto, a Nectandra lanceolata e Campomanesia xanthocarpa mostramse distribuídas de forma tipicamente decrescente. Além disso, verifica-se, através da análise da amplitude das distribuições, que apenas Ocotea porosa atinge as classes de diâmetro superiores, enquanto a maioria das espécies se limita às classes de diâmetro inferiores a $60 \mathrm{~cm}$. Esse fato, provavelmente, seja gerado por duas características intrínsecas a cada espécie - seu tamanho-limite e sua longevidade - e uma característica ecológica - a competição. Algumas espécies possuem tamanhos-limite maiores do que outras, por exemplo não existe Ilex paraguariensis com $150 \mathrm{~cm}$ de diâmetro, da mesma forma que não existe Mimosa scabrella com 300 anos. No entanto, podem existir espécies que atingem

R. Árvore, Viçosa-MG, v.30, n.2, p.283-295, 2006 
os 300 anos e os $150 \mathrm{~cm}$ de diâmetro, mas que, apesar de serem muito velhas, são muito finas, pois se encontram dominadas dentro da comunidade.

Assim, a amplitude diamétrica de uma espécie é fruto da interação da idade dos seus indivíduos, com seu tamanho potencial inerente e com a capacidade de competição de seus indivíduos na floresta, ou seja, das características auto-ecológicas da espécie.

\section{CONCLUSÕES}

Com base nas informações obtidas sobre a estrutura diamétrica no período compreendido entre 1979 e 2000 de uma Floresta Ombrófila Mista, é possível concluir que:

- A floresta e todas as parcelas apresentaram distribuição diamétrica decrescente na forma J-invertido, contudo a freqüência de indivíduos nas classes diamétricas superiores (acima de $50 \mathrm{~cm}$ ) aumentou significativamente em 2000.

- Algumas das espécies mais características da floresta não apresentaram distribuição diamétrica na forma de J-invertido, entre elas citam-se: Matayba elaeagnoides e Ocotea porosa.

- A floresta apresentou uma taxa de mortalidade de $24,05 \%$ e uma taxa de ingresso de $27,71 \%$, ou seja, houve aumento líquido de 3,66\% no número de indivíduos no período analisado. Entre as parcelas, houve variações, algumas aumentaram o número de indivíduos e outras, diminuíram.

- A idéia de que uma grande quantidade de indivíduos de uma espécie nas classes inferiores (distribuição exponencial negativa) indica que essa espécie vai estar garantida na estrutura futura da floresta nem sempre é verdadeira. A Araucaria angustifolia estava longe de apresentar tal distribuição em 1979, contudo não só manteve sua participação na floresta em 2000, como também a aumentou. Foto oposto ocorreu com Ilex dumosa, que em 1979 exibiu grande quantidade de indivíduos nas primeiras classes de diâmetro (279), e em 2000 viu essa quantidade ser fortemente reduzida, caindo para apenas 42 indivíduos.

- Se uma espécie tem poucos indivíduos nas classes inferiores, mas pequena probabilidade de morrer devido à competição, é bem provável que tal espécie se mantenha na floresta. No entanto, uma espécie na qual grande parte dos indivíduos esteja sujeita a morrer devido à competição necessita apresentar grande freqüência nas classes diamétricas inferiores para ter alguma chance de sobreviver na comunidade.

\section{REFERÊNCIAS BIBLIOGRÁFICAS}

\begin{abstract}
ALDER, D.; SYNNOTT, T.J. Permanent sample plot techniques for mixed tropical forest. Oxford: Oxford Forestry Institute, Department of Plant Sciences, University of Oxford, 1992. (Tropical Forestry Papers, 25).
\end{abstract}

BARROS, P. L. C. Estudo das distribuições diamétricas da floresta do Planalto Tapajós - Pará. 1980. 123f. Dissertação (Mestrado em Ciências Florestais) - Universidade Federal do Paraná, Curitiba, 1980.

CARVALHO, P. E. R. Espécies florestais brasileiras. Brasília: Embrapa Florestas, 2003. 1039p.

CORAIOLA, M. Caracterização estrutural de uma Floresta Estacional

Semidecidual localizada no município de Cássia - MG. 1997. 196f. Dissertação (Mestrado em Ciências Florestais) - Universidade Federal do Paraná, Curitiba, 1997.

CAStella, P. R.; BRITEZ, R. M. A floresta com araucária no Paraná: conservação e diagnóstico dos remanescentes

florestais. Brasília: Fundação de Pesquisas

Florestais do Paraná. Brasília: Ministério do Meio Ambiente, 2004. 236p.

DURIGAN, M. E. Florística, dinâmica e
análise protéica de uma Floresta
Ombrófila Mista em São João do
Triunfo - PR. 1999. 125f. Dissertação
(Mestrado em Engenahria Florestal)-
Universidade Federal do Paraná, Curitiba, 1999.

GAUTO, O. A. Análise da dinâmica e

impactos da exploração sobre o estoque remanescente (por espécies e por grupos de espécies similares) de uma Floresta Estacional Semidecidual em Missiones, Argentina. 1997. 133f.

Dissertação (Mestrado em Ciências Florestais) Universidade Federal do Paraná, Curitiba, 1997. 
GOLDSMITH, F. B.; HARRISON, C. M. Description and analysis of vegetation. In : CHAPMAN, S.B. (Ed.) Methods in plant ecology. London: Blackwell Scientific Publications, 1976. p. 85-155.

HUSCH, B.; MILLER, C. I.; BEERS, T. W. Forest mensuration. 3 ed. New York: John Wiley \& Sons, 1982. 402p.

IBGE. Manual técnico da vegetação brasileira. Rio de Janeiro: 1992. 92p. (Série Manuais Técnicos em Geociências, 1).

LEAK, W. B. An expression of diameter distribution for unbalanced, uneven-aged stands and forests. Forest Science, v. 10, n.1, 1964.

LOETSCH, F.; ZÖHRER, F.; HALLER, K. E. Forest inventory. München: BVL Verlagsgesellschft, 1973. v.2.

LONGHI, S. J. A estrutura de uma floresta natural de Araucaria angustifolia (Bert.) O. Ktze, no sul do Brasil. 1980. 198f. Dissertação (Mestrado em Engenharia Florestal) -Universidade Federal do Paraná, Curitiba, 1980.

MAACK, R. Geografia física do Estado do Paraná. Curitiba: José Olympio, 1968. 450p.

MACHADO, S. A.; BARTOSZEK, A. C. P. S.; OLIVEIRA, E.B. Estudo da estrutura diamétrica para a Araucaria angustifolia em florestas naturais na região sul do Brasil. Floresta, v. 26, n. $1 / 2$, p. $59-70,1998$.

MASER, C. Sustainable forestry:

philosophy, science and economics. Delray Beach: St. Lucie Press, 1994. 393p.

MEYER, H. A. Management without rotation. Journal of Forestry, v. 41, p.126-132, 1943.
. Structure, growth, and drain in balanced uneven-aged forests. Journal of Forestry, v. 50, p.85-92, 1952.

Forest mensuration. State College, Pa.: Renns Valley Publishers, 1953.

OLIVER, C. D.; LARSON, B. C. Forest stand dynamics. New York : John Wiley \& Sons, 1996.

PEDEN, L.M.; WILLIAMS, J. S.; FRAYER, W. E. A Markov model for stand projection. Forest Science, v.19, n. 1, p.303-314, 1973.

PIZATTO, W. Avaliação biométrica da estrutura e da dinâmica de uma Floresta Ombrófila Mista em São João do Triunfo - PR: 1995 a 1998. 1999. 172f. Dissertação (Mestrado em Engenharia Florestal) - Universidade Federal do Paraná, Curitiba, 1989.

PULZ, F. A. Estudo da dinâmica e a modelagem da estrutura diamétrica de uma floresta semidecídua montana na região de Lavras-MG. 1998. 156f.

Dissertação (Mestrado em Engenharia Florestal) Universidade Federal de Lavras, Lavras, 1998.

RODRÍGUEZ TELlo, J. C. Eficiência e custos de diferentes formas e tamanhos de unidades de amostra em uma floresta nativa de Araucaria angustifolia (Bert.) O. Ktze no sul do Brasil. 1980. 126f. Dissertação (Mestrado em Engenharia Florestal) - Universidade Federal do Paraná, Curitiba, 1980.

SCHAAF, L. B. Florística, estrutura e dinâmica no período 1979-2000 de uma Floresta Ombrófila Mista localizada no Sul do Paraná. 2001. 131 f. Dissertação (Mestrado em Engenharia Florestal) Universidade Federal do Paraná, Curitiba, 2001. 